\title{
Examining the impact of Covid-19-related disruptions, dislocations and stressors on the academic performance of undergraduates at a diverse public university
}

Carl Stempel ${ }^{a *}$, Qais Alemi ${ }^{\mathrm{b}}$, Morgan Sanchez ${ }^{\mathrm{a}}$, and Susan Ingram ${ }^{\mathrm{a}}$

${ }^{a}$ Department of Sociology; California State University, East Bay; Hayward, CA USA

${ }^{b}$ Department of Social Work and Social Ecology, Loma Linda University, San Bernardino, CA 92408 USA

*Contact: Carl Stempel carl.stempel @ecsueastbay.edu Dept. of Sociology, 25800 Carlos Bee Blvd., California State University, East Bay, Hayward, CA 94542 USA

Objective: Investigate the influence of the stressors caused by the Covid-19 pandemic on the academic performance of undergraduate students, and their ability to concentrate on schoolwork. Participants: 1,806 students attending a racially diverse 4-year university with a high rate of first generation college students.

Methods: An online survey utilizing measures of depression (PHQ-9), generalized anxiety (GAD-7), faculty and academic advising support, economic insecurity, studying conditions, family conditions, trouble concentrating on schoolwork, and academic performance. OLS regression is used to explain academic performance and trouble concentrating.

Results: Four of five students reported trouble concentrating, and trouble concentrating strongly decreased academic performance. Faculty and peer advising support and adequate studying conditions improved academic performance. Depression strongly increased trouble concentrating. Adequate studying conditions and academic advising support improved concentration.

Conclusions: In the upcoming year, faculty and student support services should highlight mental health issues and services, and increase supports for students experiencing distress.

Keywords: Covid-19, academic performance, stressors, depression, trouble concentrating 


\section{Introduction}

In March, 2020, as Covid-19 spread throughout California, California State University, East Bay (CSUEB) rapidly closed most campus offices and moved courses online. This move coincided with local and statewide shelter-in-place orders for everyone except for those engaged in essential activities. This study reports on the challenges students faced during the Spring 2020 semester based on a survey of CSUEB undergraduates completed shortly after the term. In addition to the fears and uncertainty of the global pandemic, students experienced dislocations and rapid changes in their work, family, school, and social lives. Therefore, we adopt a social stress and social support model ${ }^{1,2}$ focusing on the disruptions and stressors affecting undergraduate students' academic performance and ability to concentrate on school work. Stressors included the shift to online instruction, facing disorganized courses after the move to online, lack of adequate studying conditions, financial and material insecurity, and stressful family conditions. We also test for the influence of three forms of social support - from family, professors, and university support systems, along with a measure of depressive symptomatology. We hypothesized that academic performance and the ability to concentrate on schoolwork would be significantly influenced by these factors in multivariate regression models. Moreover, we conceptualize the effects of Covid-19 on student performance as operating through several pathways including exacerbating pre-existing mental disorders, disrupting studying patterns, increasing school-related stress and uncertainty, heightening economic insecurity, and compromising systems of support.

A recent Kaiser Health Foundation survey conducted in mid-April of 2020 found that $56 \%$ of U.S. adults reported that worry or stress around Covid-19 had caused them to experience a mental health related problem. The age group reporting the greatest stress-related effects from coronavirus were young adults, ages $18-29 .{ }^{3}$ While the psychological impact of the Covid-19 
pandemic has been recognized as an imminent threat to the health and well-being of the public, ${ }^{4}$ little empirical evidence exists on this relationship. And investigating this among college students could contribute to informing the "development of courses of action and public health messaging that can better support college students in this crisis." ${ }^{5}$

College students are known to already carry a high burden of psychological distress (depression and anxiety) as demonstrated across a wide-range of peer-reviewed studies consolidated in recent systematic reviews. ${ }^{6-8}$ Additionally, seminal works by Eisenberg et al. ${ }^{9}$ and Hysenbegasi et al. ${ }^{10}$ show that psychological distress impacts students' academic performance and course completion, and several studies report the widespread prevalence of academic stress and its socio-economic, health, and mental health correlates. ${ }^{7}$ To the best of our knowledge, none of the studies included in the aforementioned reviews were conducted in the context of a pandemic, epidemic or infectious disease outbreak. However, the American College Health Association's ( $A C H A$ ) recent survey found an increased prevalence of depression among U.S. college students surveyed in March through May 2020 compared to Fall 2019. ${ }^{11}$ There was also an increase in students reporting that their mental health had negatively impacted their academic performance. Additionally, two-thirds of students reported that their financial situations had become more stressful. On a positive note, fully $78 \%$ of students reported that their professors have been supportive during the pandemic. Other than the ACHA report, a literature search conducted in PubMed and Google Scholar returned nothing pertaining to the health, mental health, and well-being of U.S. college students during this pandemic. The studies that we found were of college students in China, revealing elevated levels of anxiety and depression ${ }^{12,13}$ and that financial burdens and family stressors exacerbate mental health problems. ${ }^{12}$ 


\section{The Covid-19 Crisis at CSU East Bay}

By March 7, 2020 there were 100 confirmed cases in California, and the Elk Grove Unified School District became the first California school district to close for Coronavirus. While CSU administrators debated on the proper course of action, CSUEB students were already taking to social media to discuss possible disruptions. Using outlets like r/CSUEB, a Reddit forum, students shared news articles about possible closures and discussed how classes might change. Many posts expressed an air of anxiety. When nearby San Jose State announced their closure and move to online, students wondered if East Bay would close too. Some questioned the university's commitment to student health, circulated petitions to cancel classes, and expressed confusion about the lack of communication from the university.

Student concerns changed markedly as the university transitioned to online classes. Many discussed the challenges they faced in completing their coursework. Concerns included their inability to concentrate at home, needing help finding emergency financial assistance, loss of inperson interactions, and sadness over cancelled graduation ceremonies.

On Tuesday, March 10, President Morishita canceled classes until Monday, March 16 at which time they would reopen with fully online instruction. This provided three days and a weekend for faculty to transform their in-person classes to online mode, setting up a steep learning curve for the many faculty who began the term teaching in-person. (Seventy-three percent of our respondents reported beginning spring semester in all or mostly in-person classes.) We heard from numerous faculty about how hard they worked to move their classes online. Faculty strategies varied from maintaining their existing class schedule and holding class meetings over zoom to delivering their classes entirely asynchronously.

The faculty members we spoke with understood that Covid-19 was disruptive and unsettling for students. Many began their first zoom class meetings with opportunities for 
students to ask questions and vent. On top of the uncertainty and fear of the contagious and deadly virus, many students' school, work, and family lives were being disrupted, in some instances drastically changing their study patterns. After the library shut down the school's remaining study area on March 28, students who relied on the campus for internet access and quiet study places lost these important resources. Survey responses illustrated the extent of this disruption: $22 \%$ of students disagreed that during shelter-in-place they had reliable internet, $10 \%$ disagreed that they had access to a working computer when they needed it, $43 \%$ disagreed that they had a quiet place to study, $52 \%$ agreed that family conflicts made it difficult to do schoolwork, and 39\% agreed that caring for family members made it difficult to do schoolwork. Sheltering-in-place meant that $26 \%$ of East Bay students had children home from school or day care, disrupting their usual study patterns.

In response to the stresses and disruptions, the university switched the default grading pattern to A,B,C, No Credit and implemented rules allowing students to withdraw from classes or switch a course to Credit/No Credit up until the end of the term. No Credit grades did not count towards students' GPAs, although rules requiring a minimum number of completed units for financial aid eligibility were not relaxed. Faculty learned that they needed to be more accommodating because of the difficulty some students were having focusing and concentrating on schoolwork and completing assignments. Many faculty reduced course workloads and allowed late submissions. One consequence of these accommodations may be that more students reported that their GPA improved in Spring 2020 (36\%) than said it declined (29\%). Judging from student responses to open-ended and fixed choice questions the degree of faculty accommodations varied, but a large majority of students reported that most faculty were accommodating. When asked to agree or disagree with the statement, "My professors were 
understanding when students needed more time to complete work," 67\% agreed (39\% strongly agreed), while only $18 \%$ disagreed.

\section{Economic Insecurity, Family Stressors, and COVID-19}

Many CSUEB students work part-time or fulltime to pay for their college education or support their families. Fully $40 \%$ of respondents reported being furloughed or laid off from a job because of Covid-19, although some of these found other work. Another less common but significant form of disruption was taking on additional hours to help their family in economic crisis. Ten percent of CSUEB students reported increasing their hours of employment during Covid-19. Students' family members also experienced high levels of economic dislocation. Almost 3/5 $(59 \%)$ of students reported that a family member whom they rely on for financial support was laid off or had their hours "cut back substantially" and $41 \%$ of these had two or more family members lose a job or experience significant cutbacks.

Job losses and cutbacks went hand in glove with high levels of economic insecurity. Onethird $(33 \%)$ of respondents said they or their family could not pay some of their bills this month, and only $30 \%$ reported that their family had a rainy day fund to cover 3 months of expenses in an emergency. Twenty-eight percent of respondents were "very" or "extremely" worried about their family's financial situation and another 30\% reported being moderately worried. Under 2\% (29 of 1802) reported being homeless sometime in the last two months and $45 \%$ percent had experienced some form of food insecurity in the last 30 days.

\section{“It was hard to stay focused and most days I was unmotivated to work on assignments."}

Reviewing responses to fixed-choice and open-ended questions, and drawing on discussions with students, we found that a central source and indicator of stress for students was their difficulty concentrating on schoolwork and completing assignments. High percentages of students reported 
difficulty concentrating on schoolwork after the shelter-in-place began. Table 1 shows the responses to the five items making up our 'trouble concentrating and doing schoolwork' index (hereinafter 'trouble concentrating'). Over $4 / 5$ of students $(81 \%)$ reported that after shelter-inplace it was somewhat harder $(26 \%)$ or a lot harder $(56 \%)$ to focus on schoolwork. Just over half (51\%) agreed that they had trouble completing schoolwork on time and $50 \%$ agreed that they often found schoolwork unimportant. Over 1/3 (34\%) agreed that their lives were so disrupted that they could not do schoolwork.

[Insert Table 1 here]

Thus, we hypothesized that students' were facing a wide range of stressors and high levels of distress that had negatively influenced academic performance and their ability to focus on schoolwork. We also expected perceived family, professor, and other university support services to improve academic performance and ability to concentrate. We hoped to learn which factors most influenced academic performance and difficulty concentrating, with an eye to ways our university may better support students in our upcoming online Fall 2020 semester. In this regard, we were particularly interested in the role of studying conditions, psychological distress, professor support, and other sources of university support.

\section{Methods}

\section{Setting, Participants and Procedures}

CSU East Bay is a public university in Hayward, California, 12 miles south of Oakland, CA in the San Francisco Bay Area. Undergraduate students at CSUEB (population 12,607 in fall 2019) match the Kaiser survey's profile of those most affected psychologically by coronavirus. ${ }^{3}$ In addition to most students being in the $18-29$ age category, $60 \%$ are women, $62 \%$ are first generation college students, $51 \%$ are Pell Grant eligible, and $85 \%$ are non-white $-37 \%$ Latino, 
23\% Asian American (Filipinos are the largest subgroup), and 10\% African American. The CSUEB Covid-19 Student Survey was an online survey of undergraduates conducted between May 18 and June 1, 2020. All enrolled CSUEB students received multiple email and text invitations to participate in the study beginning four days after the last day of final exams, to limit the influence of the immediate distress of finals week. The questionnaire took 15-20 minutes to complete and consisted of fixed-choice and two open-ended questions. A consent form appeared on the first page describing the purpose of the study, their rights, and the risks associated with participating. Students were encouraged to skip upsetting questions and the survey ended with links to mental health support services. We received 1,806 completed surveys for a $15 \%$ response rate $(11,959$ undergraduates were enrolled in spring 2020$)$. The questionnaire and plans for protecting human subjects were approved by CSUEB's Institutional Review Board.

\section{Dependent Variables}

Academic Performance. We developed a three-item index for measuring academic performance. It included two items on number of courses improved or declined in after shelterin-place and a question assessing overall improvement or decline in GPA in during spring semester (see Table 2 below for wording). Thus, this scale measured students' academic performance relative to previous terms and relative to before the shelter-in-place order. Items were weighted equally with higher scores indicating high academic performance. [Insert Table 2 here]

Difficulty Concentrating on Schoolwork. This five-item index included four items asking respondents to rate on a five-point Likert-type scale their difficulty concentrating on and completing schoolwork, feelings that schoolwork was unimportant, and the degree to which life disruptions made schoolwork undoable. A fifth item asked how much they thought focusing on 
schoolwork was easier or harder since COVID-19. (See Table 1 for wording.) Items were weighted equally with higher scores indicating greater difficulty concentrating.

\section{Independent Variables}

Our independent variables included eight social background variables, two control variables, and a range of social stress and social support explanatory variables that measured conditions created by or were exacerbated by the pandemic.

Social background and control variables. We assessed age, gender, year in school, race/ethnicity, college within the university, if the respondent was born in the U.S., family income, and if the respondent was a first generation college student. For family income we expected that many students would not accurately know their family's income, so our question presented respondents with the median family income for Alameda County and asked if their family was lower, lower middle, middle, upper middle, or upper income. We included selfreported GPA as a control for previous academic performance and as a proxy control for previous difficulty concentrating, reasoning that students with higher overall GPAs have had less difficulty concentrating in the past. (GPA and trouble concentrating have a Pearson's $r$ of .161, $\mathrm{p}<.001$.) Proportion of classes online at the beginning of the term does double duty as a control for the change in the modality of teaching, thus focusing our findings on the broader COVID-19 crisis, while also providing an estimate of the stress of moving online.

Social stress and social support variables. We included measures of economic distress and dislocation, access to adequate studying conditions, family dynamics/conditions, the proportion of courses that students reported were "well-organized" after shelter-in-place, selfreported overall GPA, perceived university and faculty supports, proportion of online classes students began the term with, and psychological distress. 
The measures of 'economic distress and dislocation' were: financial insecurity (3 items); food insecurity (3 items); experienced homelessness during shelter-in-place; if respondent was laid off or furloughed during shelter-in-place; and, if a family member the respondent relied on financially was laid off or had their work hours cut back substantially. Financial insecurity included two items ('cannot pay all bills this month;' 'does not have a 3 month emergency fund') replicating a recent Pew Center survey of U.S. adults ${ }^{14}$ and one item used by the American National Election Survey ('worry about current financial situation'). ${ }^{15}$ The food insecurity questions replicated items from the 2018 \#RealCollege Survey that CSUEB students participated in. $^{16}$

The perceived university support questions were designed to capture confidence that support was available if needed, such as this example, "Throughout this semester, I knew... I could rely on professor(s) I could reach out to for help if I was struggling academically." Perceived faculty support focused on students' confidence that they could turn to professors for help if they were getting behind or struggling in the class, or if they needed extra time to complete an assignment. University support variables included perceived faculty support (3 items), perceived peer tutoring and mentoring support (2 items), perceived psychological counseling support ( 1 item); perceived academic advising support (1 item). We reasoned that confidence in the potential sources of support would contribute to students' sense of academic security, thus increasing their ability to concentrate. We conceptualize these sources of support as social or institutional sources of resilience. ${ }^{17}$

The access to 'adequate studying conditions' index asked about reliable access to the internet, a computer, and a quiet place to study or read. Family dynamics variables included number of child(ren) age 18 or under home from school or daycare, how much family conflict interfered with schoolwork, how much family care responsibilities interfered with schoolwork, 
and perceived family support included three items: academic, financial, and "to talk with and get help from."

Lastly, the 'psychological distress' measures were the PHQ-9 measure of depression (9 items) and the GAD-7 measure of generalized anxiety (7 items). The PHQ-9 turned out to be far more influential. It scores each of the nine DSM-IV criteria as $0=$ "not at all" to 3 "nearly every day." Its developers recommend the following guidelines for interpreting scores on the PHQ-9: 0-4 = no depression, 5-9 = mild depression, 10-14 = moderate depression, $15-19=$ moderately severe depression, and $20-27=$ severe depression. $^{18}$

\section{Data Analysis}

Data analyses were conducted using SPSS version 25.0. Indexes were tested using Principal Components Analysis with the criteria that the items generated only one component (Eigenvalue 1.0 or higher, varimax rotation) and each item was correlated with the component at 0.6 or higher. Residuals in all regression models were normally distributed and homoscedastic, and the predictors exhibited no instances of multicollinearity. Most survey questions had minimal missing data. We preserved cases for the social background and control variables by including the missing cases as a separate dummy variable for categorical variables and replacing missing cases with the mean for three continuous variables. We did not replace missing cases in the explanatory or dependent variables. This strategy led to missing cases ranging from $2 \%$ to $5 \%$ in the multivariate regressions and less than $2 \%$ for bivariate relationships. In regressions all variables were scaled from 0 to 1.0 making unstandardized betas comparable and interpretable as the proportion of the dependent variable range predicted by the low and the high ends of each independent variable.

First, we carried out univariate analyses on all independent and dependent variables for descriptive purposes. Secondly, we examined bivariate relationships between all independent and 
dependent variables by generating unstandardized regression coefficients. For parsimony, factors significant at the bivariate level were tested in multivariate regression models predicting academic performance and trouble concentrating.

We then conducted two sets of multiple regressions, one each for the two dependent variables. Details are described in the findings. Our strategy was to first look at the influence of the social background variables with the two controls. Then we used the social background and controls as control variables in models testing the influence of the stressors and support variables, and then to test the influence of psychological distress factors. Finally, we present a full model combing the statistically significant stressors, supports, and psychological distress factors. For all models we report $\mathrm{R}^{2}$, change in $\mathrm{R}^{2}$, beta weights, and their associated $\mathrm{p}$-values. All results presented here are weighted (raking) using population figures provided by CSUEB's Department of Institutional Effectiveness and Research for gender, school standing, college within the university (Business, Science, Education and Allied Sciences, Humanities and Social Sciences), and whether or not the student is a first-generation college student. We were unable to weight by race because our survey question used additional categories and found more mixedrace respondents and fewer non-responses than the school census.

\section{Results}

\section{Descriptive Analysis}

Table 3 describes sample characteristics for the 1,806 participants completing our survey. Participants were mostly female, Latino, juniors and seniors, first generation college students, and U.S. born. Using PHQ-9's established cut points ${ }^{19}$ we found that $49 \%$ of CSUEB students scored in the moderate depression range or higher (10 out of 27 or higher). Strikingly, 15\% percent scored in the severe depression range and $16 \%$ scored in the moderately severe 
depression range. PHQ-9 items ask respondents about experiences during the last two weeks. Thus, to assess the possible influence of finals week stress on depression scores we compared the 279 students who completed the survey more than two weeks after final exams to those whose two week window included part of finals week. The mean scores for respondents who completed the survey before and after the two week window were quite close, 10.7 and 10.5 respectively.

Table 3 reports bivariate unstandardized regression coefficients for all independent variables explaining our two dependent variables, academic performance and trouble concentrating. Looking at the influence of social background variables on academic performance we see that women, juniors and seniors, Asian Americans, and those from higher income families performed modestly better than men, freshmen and sophomore, whites, those born in the U.S., and lower income students. Both control variables, proportion of courses online at beginning of the term and overall GPA, were positively related to academic performance. Turning to the explanatory variables, with one exception, all of the family dynamics, economic distress and dislocation, studying conditions, university support, and psychological distress/functioning variables were associated in the expected direction with school performance at $\mathrm{p}<.05$. The exception was a non-significant relationship with the respondent experiencing a job layoff. Having trouble concentrating on schoolwork was by far the most influential variable explaining school performance $(b=.52)$, followed by having good study conditions (reliable internet, computer, quiet place to study) $(b=.32)$, depression $(b=.32)$, perceived professor support $(b=.30)$, proportion of courses that were well-organized after shelter in place $(b=.27)$, and generalized anxiety $(b=.27)$.

Turning to the social background variables explaining 'trouble concentrating,' students in the humanities and social sciences, freshmen and sophomores, first-generation in college, Latinx, Middle Eastern, mixed race, those born in the U.S., and lower income students had more trouble 
concentrating on schoolwork. These relationships are all weak to modest in strength. The two control variables were also significant in the expected direction, with overall GPA having a moderately strong relationship at $b=.20$. Among the explanatory variables, three stand out as very strongly associated with trouble concentrating: depression $(b=.56)$, generalized anxiety $(b=.46)$, and having adequate study conditions $(b=.41)$. In addition, family conflict, caring for family members interfering with schoolwork, perceived family support, proportion of courses well-organized, perceived professor support, and perceived peer academic support all had betas above $b=.25$, indicating considerable strength $(\mathrm{p}<.001$ for all). The economic distress/dislocation variables were the least influential, although homelessness, food insecurity, and financial insecurity all moderately increased trouble concentrating.

\section{Multivariate Regression Analyses}

\section{Models Predicting Academic Performance}

Table 4 reports results of four regressions explaining academic performance controlling for social background characteristics, which are not shown to limit clutter. Among the background and control variables, we found that those with a higher class rank (Juniors and Seniors) $(b=.05)$, women $(b=.03)$, Asian Americans $(b=.04)$, higher income $(b=.06)$, higher GPA $(b=.08)$, and those who started the term in more online classes $(b=.07)$ all performed modestly better ( $\mathrm{p}<.05$ or lower for all). Overall, the social background and control variables combined explained a modest $3.0 \%$ of the variance in academic performance. All subsequent models control for the social background and control variables. In Tables 3 and 4 we report betas for our two primary controls, overall GPA and proportion of courses online at term start, in all models.

Next, in a preliminary step we ran four regressions to identify which social stress and social support variables to include, testing variables grouped by economic insecurity and 
disruption, family dynamics, study conditions, and university support (including proportion of well-organized courses). Five variables were non-significant and were dropped from the analysis: food insecurity, being laid off or furloughed, number of children home from school or daycare, perceived academic advising support, and perceived psychological counseling support. Model 1 in Table 4 includes all the stressor and support variables which had significant independent effects $(\mathrm{p}<.05)$ in the preliminary regressions. It shows that having good study conditions $(b=.15)$, perceived professor support $(b=.13)$, and having well-organized classes $(b=.13)$ were most influential in explaining academic performance. The remaining variables were also significant at $\mathrm{p}<.05$ except for having a family member lose a job. The model as a whole explains $24 \%$ of the variance in academic performance.

Model 2 adds the PHQ-9 depression scale to the background and control variables $(b=$ .33 ), showing that it explained a substantial additional $11.7 \%$ of the variance in academic performance. We also ran a model (not shown) including GAD-7 with PHQ-9. PHQ-9 was far more influential and GAD-7, although significant at $\mathrm{p}<.05$, added only $0.3 \%$ of additional explained variance. Thus we dropped GAD-7 dropped from the analysis for the sake of analytical and conceptual clarity and parsimony.

In Model 3 we added our trouble concentrating scale to Model 2. It was very influential predictor of academic performance $(b=.49)$ and explained an additional $16.4 \%$ of the variance. The addition of trouble concentrating also dramatically reduces the influence of PHQ-9 to $b=-$ .06. Thus, much of the influence of depression on academic performance can be attributed to depression's influence on trouble concentrating or vice-versa. PHQ-9 has an item on difficulty concentrating. To remove this overlap we created an 8-item version that eliminated the concentration item and then reran Model 3. This increased the additional variance explained by 
trouble concentrating to $17.3 \%$, with $b=-.05$ for depression and $b=-.49$ for trouble concentrating.

Model 4 is our full model created by adding to Model 3 the explanatory variables in Model 1 that were significant at $\mathrm{p}<.05$. We see that with depression and trouble concentrating as controls, perceived professor support $(b=.12)$ and homelessness $(b=-.09)$ are the two most influential stressor or support variables, followed by adequate studying conditions $(b=.07)$ and level of class organization $(b=.08)$. Depression is no longer significant at $\mathrm{p}<.05$ and the influence of trouble concentrating $(b=-.42)$ dwarfs the other explanatory variables. [Insert Table 3 here]

Comparing the unstandardized betas for the non-psychological explanatory variables in Models 1 and 4 sheds light on which of these are most intertwined with depression and trouble concentrating. The betas for food insecurity and homelessness were reduced modestly (15\% and $1 \%$ respectively), suggesting that these forms of material deprivation negatively affected school performance irrespective of their associations with levels of concentration and psychological distress. Likewise, the perceived professor support effect was reduced a modest $12 \%$. On the other end of the spectrum, the negative influence of levels of family conflict was completely removed by the controls, suggesting that the negative influence of family conflict is mediated by or intertwined with trouble concentrating or depression. Family conflict has strong Pearson's r's with depression (.33) and trouble concentrating (.42). Similarly, the psychological controls reduced the effect for caring for family members by $57 \%$, perceived peer academic support by $50 \%$, perceived family support by $49 \%$, and having good studying conditions by $48 \%$.

Because of the crucial role professors played in providing accommodations for struggling students, we suspected that perceived professor support most affected academic performance for those who had high levels of trouble concentrating. To test this we ran an additional regression 
(not shown) adding to Model 4 an interaction term for perceived professor support $\mathrm{x}$ trouble concentrating. Figure 1 plots this interaction showing that indeed professor support improved academic performance much more for students with high levels of trouble concentrating. [Insert Figure 1 here]

\section{Models Predicting Difficulty Concentrating on Schoolwork}

The tremendous influence of 'trouble concentrating' on academic performance and the prominence of this variable in students' qualitative responses led us to explore its correlates in a series of regressions explaining trouble concentrating. We first computed a regression with the social background and control variables (not shown) finding that students in the humanities and social sciences $(\mathrm{b}=.05)$, Latinx $(\mathrm{b}=.06)$ and Middle Eastern $(\mathrm{b}=.08)$ students, and those born in the U.S. $(b=.04)$ had modestly more difficulty concentrating compared to students in the 'hard' sciences, whites, and those born outside the U.S. respectively ( $p<.05$ for all). In addition, the two controls were significant at $\mathrm{p}<.001$ : students who began the term in a higher proportion of online classes $(b=-.07)$ and students with higher overall GPAs $(b=-.19)$ had lower levels of trouble concentrating. Combined the social background and control variables explained a modest $5.0 \%$ of the variance, and the social background variables alone explained only $2.3 \%$ of the variance.

We then did preliminary regressions entering groups of explanatory variables like those described above for the academic performance regression. Based on the preliminary regressions we dropped five variables: if the respondent had been laid off, the financial distress index, experiencing homelessness, number of children home from school, and perceived support from psychological counselors. Model 1 in Table 5 reports findings from a regression entering the remaining stressor and support variables with controls. The most influential variables were access to adequate study conditions ( $b=-.17)$, family conflict $(b=.14)$, and level of course 
organization $(b=-.14)$. Combined, the variables explained an additional $29.6 \%$ of the variance in trouble concentrating. Neither of the remaining economic distress and dislocation variables had a significant relationship controlling for the other variables.

Model 2 reports the influence of depression (PHQ-9) on trouble concentrating. With controls, moving from low to high on depression changes predicted values fully .54 of the trouble concentrating range $(b=.54)$ and depression explains an additional $29.9 \%$ of the variance. Removing the concentration item from PHQ-9 only slightly lowers the influence of depression $(b=.53)$. Model 3 reports the full model which adds the significant social risk and social support explanatory variables in Model 1 to Model 2. Model 3 explains $45.3 \%$ of the variance in the trouble concentrating with depression being by far the most influential variable $(b=.37)$. Good studying conditions, $(b=-.11)$, family conflict $(b=-.11)$, and course organization $(b=-.10)$ are the most influential of the remaining variables.

Finally, we compared the reduction in unstandardized betas for the stressors and support variables between Model 1 and Model 3 to consider the ways depression is implicated in these variables. The biggest reduction is a $74 \%$ decline in the beta for perceived family support, which is also moderately strongly correlated with depression. In addition, betas for Perceived Peer Academic Support and Perceived Academic Advising Support declined 45\% and 50\% respectively (both are negatively correlated with PHQ-9), suggesting that institutional academic support may have reduced trouble concentrating in part by lowering levels of psychological distress.

\section{Discussion}

We conducted a survey of 1806 undergraduates at CSUEB, applying a social stress and social resilience model to understand how the disruptions and stressors of Covid-19 affected students' academic performance and ability to concentrate on schoolwork during the Spring 2020 
semester. Our most important findings were higher percentage of students who reported difficulty focusing on schoolwork - more than $4 / 5$ (81\%) of students said it was harder to focus on schoolwork after Covid-19. Further, we found that students' difficulty concentrating greatly influenced their academic performance. Conversations with professors and survey findings indicate that many professors were attuned to this problem and supported students with accommodations such as extra time to complete assignments. We then found that psychological distress, especially in the form of high levels of symptoms of depression, was a huge burden on students' mental health that greatly influenced their difficulty concentrating and through this their academic performance, which confirmed our hypotheses. Forty-nine percent of students exceeded the usual cut-off point for risk of major depression on the PHQ-9. This is much higher than the $30 \%$ prevalence rate observed among undergraduate students from various regions and that of the U.S. general population $(9 \%) .{ }^{6}$ Further, it is eight percentage points higher than the ACHA survey found for students they surveyed in Spring 2020. ${ }^{11}$ Our findings parallel and specify, under Covid-19 crisis conditions, previous research showing a robust association between depression and poor academic productivity. ${ }^{9,10}$

While thorough evidence on the psychological impacts of Covid-19 on general populations does not exist, ${ }^{20}$ its debilitating effects appear evident in CSUEB undergraduates, which aligns with findings from the ACHA survey ${ }^{11}$ and with our expectations rooted in the social stress and social support model applied here. ${ }^{1-2}$ Although we cannot assert a causal relationship due to our study design, we argue that depressive symptoms for some may have been intensified by and operating through a range of risk factors, either induced or exacerbated by this pandemic — ultimately affecting academic performance and ability to concentrate on school work. Evidence of this confluence is demonstrated in the substantial mediating role depression played for several factors influencing difficulty concentrating, including family 
conflict, perceived academic advising support, perceived peer advising support, and access to good study conditions.

Access to the basic material conditions of studying - reliable internet, a working computer, and a quiet place to study - substantially and robustly decreased students trouble concentrating and increased their academic performance. In another study ${ }^{21}$ we found that African American, Latinx, low income, and first generation students were least likely to have access to these basic studying conditions. Levels of family support, family conflict and responsibilities for caring for family members also substantially affected difficulty concentrating and academic performance. Future pandemic studies should explore family patterns in greater detail. Somewhat surprisingly, economic distress and disruption (e.g. job loss, financial insecurity, food insecurity) were not as influential as expected. Among our measures of economic insecurity, food insecurity was most strongly and robustly associated with difficulty concentrating and homelessness was most strongly associated with lower academic performance.

Students' perceived university support substantially and robustly influenced academic performance and lowered levels of trouble concentrating. The great influence of professors was highlighted by the robust influence of perceived professor support and proportion of courses that were well-organized on academic performance. The former was especially important for students with high levels of trouble concentrating. Other sources of university support were also influential. Perceived support from peer mentors and tutors was robustly associated with both academic performance and less trouble concentrating, and perceived support from academic counselors robustly lowered trouble concentrating. We must add that the four types of perceived university support (including professors) are strongly inter-correlated, suggesting that they constituted a united web of support to help students through this difficult semester. 
This brings us to two important practical takeaways as we look to the new school year. First, this study highlights the crucial role faculty support played in student success. A growing body of literature indicates that undergraduates' levels of anxiety and depression are strongly linked to feeling unsupported by faculty and teachers. ${ }^{8}$ While we can expect that courses will be, on average, better organized and we can hope that students and faculty will be better adjusted to our Covid-19 conditions, we urge professors to continue regular check-ins with students and make extra efforts to reach out to students who are struggling or falling behind. Connecting students with various university support systems is always important, but never more so than in the upcoming year. This will be especially challenging when most or all contact between faculty and students will be online.

In conclusion, this study highlights the many disruptions and dislocations that students experienced amid the Covid-19 pandemic and the extent to which these challenges impacted students' academic performance and ability to concentrate on schoolwork. Major strengths of this study include that it is one of the first to examine such challenges in U.S. college students in a Covid-19 context and the wide range of stressors investigated. However, causal inferences cannot be made due to the study's cross-sectional design and it is possible that there was a sampling bias in the $15 \%$ of CSUEB students who completed the survey.

As we are writing, media coverage of academia is reporting the high levels of psychological distress that students faced in spring and the difficulty students had gaining access to mental health services. ${ }^{22,23}$ Our study adds weight to this concern. We urge faculty, advisors, peer mentors, counselors, and the full range of student support services to expand their networks of communication about mental illness and support for those who are in distress. 


\section{$\underline{\text { References }}$}

1. Pearlin, LI. The sociological study of stress. J Health Soc Behav. 1989; 30(3);241-256.

2. Aneshensel, C. S. (1992). Social stress: Theory and research. Annu Rev Sociol. 1992; 18(1): $15-38$.

3. Kirzinger A, Hamel L, Muñana C, Kearney A, Brodie M. KFF Health Tracking Poll - Late April 2020: Coronavirus, social distancing, and contact tracing. Kaiser Family Foundation. https://www.kff.org/report-section/kff-health-tracking-poll-late-april-2020-economic-andmental-health-impacts-of-coronavirus/. Updated April 24, 2020. Accessed May5, 2020.

4. Pfefferbaum B, North CS. Mental health and the Covid-19 pandemic. New Engl J Med. 2020; Apr 13.

5. Zhai Y, Du X. Addressing collegiate mental health amid COVID-19 pandemic. Psychiatry Res. 2020; 288. doi: 10.1016/j.psychres.2020.113003. PMID: 32315885.

6. Ibrahim AK, Kelly SJ, Adams CE, Glazebrook C. A systematic review of studies of depression prevalence in university students. $J$ Psychiatric Res. 2013; 47(3):391-400.

7. Pascoe MC, Hetrick SE, Parker AG. The impact of stress on students in secondary school and higher education. Int J Adolesc Youth. 2020; 25(1):104-112.

8. Sharp J, Theiler S. A review of psychological distress among university students: Pervasiveness, implications and potential points of intervention. Int J Adv Couns. 2018; 40(3):193-212.

9. Eisenberg D, Gollust SE, Golberstein E, Hefner JL. Prevalence and correlates of depression, anxiety, and suicidality among university students. Amer J Orthopsychiat. 2007; 77(4):534-542.

10. Hysenbegasi A, Hass SL, Rowland CR. The impact of depression on the academic productivity of university students. J Ment Health Policy Econ. 2005;8(3):145.11.

11. American College Health Association. The impact of Covid-19 on college student wellbeing. https://healthymindsnetwork.org/wp-

content/uploads/2020/07/Healthy_Minds_NCHA_COVID_Survey_Report_FINAL.pdf. Updated July, 2020. Accessed August 3, 2020.

12. Cao W, Fang Z, Hou G, Han M, Xu X, Dong J, Zheng J. The psychological impact of the COVID-19 epidemic on college students in China. Psychiatry Res. 2020; 287. doi:

10.1016/j.psychres.2020.112934. PMID: 32229390.

13. Liu S, Liu Y, Liu Y. Somatic symptoms and concern regarding COVID-19 among Chinese college and primary school students: A cross-sectional survey. [published online ahead of print July 1, 2020]. Psychiatry Res. doi: 10.1016/j.psychres.2020.113070 PMID: 32422501

14. Parker K, Horowitz JM, Brown A. About half of lower-income Americans report household job or wage loss due to COVID-19. Pew Research Center. 
https://www.pewsocialtrends.org/2020/04/21/about-half-of-lower-income-americans-reporthousehold-job-or-wage-loss-due-to-covid-19/. Updated April 21, 2020. Accessed May 5, 2020.

15. American National Election Studies. User's Guide and Codebook for the ANES 2016 Time Series Study. University of Michigan and Stanford University; https://electionstudies.org/wpcontent/uploads/2018/12/anes_timeseries_2016_userguidecodebook.pdf. Updated September 4, 2019. Accessed May 5, 2020.

16. Goldrick-Rab S, Baker-Smith C, Coca V, Looker E, Williams T. College and university basic needs insecurity: A national \#RealCollege Survey report. The Hope Center at Temple University. https://hope4college.com/wpcontent/uploads/2019/04/HOPE_realcollege National_report_digital.pdf. April 2019. Accessed May 5, 2020.

17. Hall PA, Lamont M, editors. Social resilience in the neoliberal era. New York, NY: Cambridge University Press; 2013.

18. Kroenke K, Spitzer RL, Williams JB. The PHQ-9: validity of a brief depression severity measure. J Gen Intern Med. 2001; 16(9):606-13.

19. Manea L, Gilbody S, McMillan D. Optimal cut-off score for diagnosing depression with the Patient Health Questionnaire (PHQ-9): a meta-analysis. CMAJ. 2012 Feb 21;184(3):E191-6.

20. Fardin MA. COVID-19 and anxiety: A review of psychological impacts of infectious disease outbreaks. Arch Clin Infect Dis. 2020;15(COVID-19).

21. Authors.

22. Williams LB, Reetz DR. How to prepare for the coming flood of student mental health needs. The Chronicle of Higher Education Community. https://community.chronicle.com/news/2383how-to-prepare-for-the-coming-flood-of-student-mental-health-needs?cid=VTEVPMSED1. July 31, 2020. Accessed August 2, 2020.

23. Redden E. Pandemic hurts student mental health. Inside Higher Ed. https://www.insidehighered.com/news/2020/07/13/survey-finds-higher-prevalence-depressionamong-students-and-difficulties-accessing\#.Xw9gFsJtEhA.email. Updated July13, 2020. Accessed July27, 2020. 


\begin{tabular}{|c|c|c|c|c|c|c|}
\hline & $\begin{array}{l}\text { Strongly } \\
\text { disagree }\end{array}$ & $\begin{array}{c}\text { Somewhat } \\
\text { disagree }\end{array}$ & Neither & $\begin{array}{l}\text { Somewhat } \\
\text { agree }\end{array}$ & $\begin{array}{l}\text { Strongly } \\
\text { agree }\end{array}$ & $\mathrm{N}=$ \\
\hline I had trouble concentrating on schoolwork & $10 \%$ & $9 \%$ & $8 \%$ & $29 \%$ & $44 \%$ & 1801 \\
\hline I had trouble completing my school work on time & 21 & 16 & 13 & 24 & 26 & 1799 \\
\hline It often seemed like schoolwork was unimportant & 18 & 13 & 19 & 26 & 24 & 1802 \\
\hline My life was so disrupted that I couldn't do schoolwork & 27 & 19 & 20 & 21 & 13 & 1801 \\
\hline & $\begin{array}{l}\text { A lot } \\
\text { easier }\end{array}$ & $\begin{array}{c}\text { Somewhat } \\
\text { easier }\end{array}$ & Same & $\begin{array}{l}\text { Somewhat } \\
\text { harder }\end{array}$ & $\begin{array}{l}\text { A lot } \\
\text { harder }\end{array}$ & $\mathrm{N}=$ \\
\hline $\begin{array}{l}\text { Since Covid 19, was it easier or harder to focus on your } \\
\text { schoolwork, or was there no change? }\end{array}$ & $3 \%$ & $5 \%$ & $10 \%$ & $26 \%$ & $55 \%$ & 1801 \\
\hline
\end{tabular}




\begin{tabular}{|c|c|c|c|c|c|c|c|}
\hline & No & Yes, one & \multicolumn{2}{|c|}{ Yes, two } & \multicolumn{2}{|c|}{ Yes, three +} & $\mathrm{N}=$ \\
\hline Did worse in a class after we moved to shelter in place? & $47 \%$ & $26 \%$ & \multicolumn{2}{|c|}{$16 \%$} & & $11 \%$ & 1782 \\
\hline Did better in a class after we moved to shelter in place? & 50 & 22 & \multicolumn{2}{|c|}{14} & & 14 & 1790 \\
\hline & $\begin{array}{l}\text { Declined } \\
\text { great deal }\end{array}$ & $\begin{array}{c}\text { Declined } \\
\text { somewhat }\end{array}$ & Same & \multicolumn{2}{|c|}{$\begin{array}{l}\text { Improved } \\
\text { somewhat }\end{array}$} & $\begin{array}{l}\text { Improved } \\
\text { great deal }\end{array}$ & $\mathrm{N}=$ \\
\hline $\begin{array}{l}\text { Do you expect that your Grade Point Average improved, } \\
\text { declined, or stayed about the same this semester? }\end{array}$ & $7 \%$ & $22 \%$ & $35 \%$ & \multicolumn{2}{|c|}{$25 \%$} & $11 \%$ & 1796 \\
\hline
\end{tabular}




\begin{tabular}{|c|c|c|c|}
\hline & & $\begin{array}{c}\text { School Performance } \\
\mathrm{M}=.51 ; \mathrm{SD}=.26\end{array}$ & $\begin{array}{c}\text { Trouble Concentrating } \\
\text { on Schoolwork } \\
\mathrm{M}=.62 ; \mathrm{SD}=.27 \\
\end{array}$ \\
\hline & $\%(\mathrm{~N}) / \mathrm{M}(\mathrm{SD})$ & beta (sig) & $\mathrm{M}(\mathrm{SD})$ \\
\hline Female & $59 \%(1070)$ & $.03^{* *}$ & .01 \\
\hline Male (reference) & $39(700)$ & & \\
\hline Non-binary & $1 \%(25)$ & -.06 & .06 \\
\hline Sciences (reference) & $38 \%(689)$ & & \\
\hline Business/Economics & $18 \%(331)$ & -.02 & .01 \\
\hline Education and Allied Sciences & $8 \%(140)$ & -.01 & .03 \\
\hline Letters, Arts and Social Sciences & $35 \%(639)$ & -.02 & $.04 * *$ \\
\hline Freshmen and Sophomores (reference) & $22 \%(402)$ & & \\
\hline Juniors and Seniors & $78 \%(1404)$ & $.06 * *$ & $-.05 * *$ \\
\hline Not first generation college student (reference) & $39 \%(709)$ & & \\
\hline First generation college student & $59 \%(1063)$ & .00 & $.04 * * *$ \\
\hline African American & $9 \%(154)$ & .01 & .04 \\
\hline Asian American and Pacific Islander & $23 \%(414)$ & $.04 *$ & .03 \\
\hline Latinx & $32 \%(573)$ & .00 & $.10 * * *$ \\
\hline Middle Eastern, Arab, Central/Southern Asian & $5 \%(90)$ & .03 & $.07 *$ \\
\hline Native American & $0 \%(7)$ & .08 & -.15 \\
\hline White (reference) & $18 \%(333)$ & & \\
\hline Mixed Race & $12 \%(225)$ & -.01 & $.06 * *$ \\
\hline Not born in U.S. (reference) & $19 \%(334)$ & & \\
\hline Born in the U.S. & $81 \%(1465)$ & $-.04 *$ & $.04 * *$ \\
\hline Family income & $.31(.28)$ & $.06^{*}$ & $-.05 *$ \\
\hline Proportion of classes online at semester start & $.27(.32)$ & $.09 * * *$ & $-.06 * *$ \\
\hline Overall college GPA (self-reported) & $.62(.21)$ & $.09 * *$ & $-.20 * * *$ \\
\hline Family conflict made it difficult to study & $.55(.37)$ & $-.18 * * *$ & $.31 * * *$ \\
\hline Caring for family interfered with schoolwork & $.46(.37)$ & $-.16^{* * *}$ & $.28 * * *$ \\
\hline Number of children home from school/daycare & $.15(.29)$ & $-.07 * * *$ & $.06^{* *}$ \\
\hline Perceived family support (3 items) & $.58(.29)$ & $.25 * * *$ & $-.29 * * *$ \\
\hline Positive study conditions (3 items) & $.69(.25)$ & $.32 * * *$ & $-.41 * * *$ \\
\hline $\mathrm{R}$ was furloughed/laid off & $40 \%(716)$ & -.01 & $.04 * *$ \\
\hline Family member relied on financially was laid off & $59 \%(1060)$ & $-.04 * * *$ & $.06 * * *$ \\
\hline $\mathrm{R}$ was homeless sometime in the last two months & $2 \%(29)$ & $-.20 * * *$ & $.12^{*}$ \\
\hline Food insecurity (3 items) & $.20(.28)$ & $-.06 *$ & $.13 * * *$ \\
\hline Economic insecurity (3 items) & $.45(.31)$ & $-.08 * * *$ & $.12 * * *$ \\
\hline Proportion of courses well-organized after Covid & $.66(.32)$ & $.27 * * *$ & $-.28 * * *$ \\
\hline Perceived professor support (3 items) & $.64(.29)$ & $.30 * * *$ & $-.27 * * *$ \\
\hline Perceived peer academic support (2 items) & $.45(.31)$ & $.25 * * *$ & $-.27 * * *$ \\
\hline Perceived academic advising support (1 item) & $.57(.33)$ & $20 * * *$ & $-.22 * * *$ \\
\hline Perceived psychological counseling support (1 item) & $.50(.33)$ & $.18^{* * *}$ & $-.19 * * *$ \\
\hline Depression, PHQ-9 (9 items) & $.39(.28$ & $-.32 * * *$ & $.56 * * *$ \\
\hline Generalized Anxiety, GAD-7 (7 items) & $.41(.31)$ & $-.27 * * *$ & $.46^{* * *}$ \\
\hline Trouble Concentrating (5 items) & $.62(.27)$ & $-.52 * * *$ & $1.00 * * *$ \\
\hline
\end{tabular}




\begin{tabular}{|c|c|c|c|c|c|}
\hline & Model 1 & Model 2 & Model 3 & Model 4 & $\% \triangle b$ \\
\hline & $\mathrm{b}$ & $\mathrm{b}$ & $\mathrm{b}$ & B & $\begin{array}{l}\text { Models } 1 \\
\text { to } 4\end{array}$ \\
\hline Overall GPA & -.01 & .02 & -.02 & -.05 & \\
\hline Proportion courses online at start & $.05^{*}$ & $.07 * * *$ & $.04 *$ & .03 & \\
\hline Family conflict & $-.05 * *$ & & & .01 & $116 \%$ \\
\hline Family care demands & $-.07 * * *$ & & & -.03 & $58 \%$ \\
\hline Perceived family support & $.05^{*}$ & & & .02 & $55 \%$ \\
\hline Good study conditions & $.15^{* * *}$ & & & $.07 * *$ & $50 \%$ \\
\hline Family member laid off & -.01 & & & & \\
\hline Experienced homelessness & $-.09 *$ & & & $-.09 *$ & $3 \%$ \\
\hline Financial insecurity & .03 & & & & \\
\hline Courses organized after Covid & $.13 * * *$ & & & $.08 * * *$ & $41 \%$ \\
\hline Perceived professor support & $.13 * * *$ & & & $.12 * * *$ & $14 \%$ \\
\hline Perceived peer academic support & $.08 * * *$ & & & .04 & $51 \%$ \\
\hline Depression (PHQ-9) & & $-.33 * * *$ & $-.06 * *$ & .02 & \\
\hline Trouble Concentrating & & & $-.49 * * *$ & $-.42 * * *$ & \\
\hline $\mathrm{N}=$ & 1704 & 1767 & 1761 & 1709 & \\
\hline adjusted $R^{2}\left(\triangle R^{2}\right)$ & $.243(.220)$ & $.147(.116)$ & $.322(.163)$ & $.365(.051)$ & \\
\hline
\end{tabular}




\begin{tabular}{|c|c|c|c|c|}
\hline & Model 1 & Model 2 & Model 3 & $\% \triangle b$ \\
\hline & $\mathrm{b}$ & $\mathrm{b}$ & $\mathrm{b}$ & $\begin{array}{l}\text { Models } 1 \\
\text { to } 4\end{array}$ \\
\hline Overall GPA & $-.11 * * *$ & $-.10 * * *$ & $-.08 * * *$ & \\
\hline Proportion courses online at start & -.03 & $-.07 * * *$ & $-.04 *$ & \\
\hline Family conflict & $.14 * * *$ & & .11 & $20 \%$ \\
\hline Family care demands & $.10 * * *$ & & .08 & $26 \%$ \\
\hline Perceived family support & $-.07 * *$ & & -.02 & $74 \%$ \\
\hline Good study conditions & $-.17 * * *$ & & -.11 & $38 \%$ \\
\hline Family member laid off & .00 & & & \\
\hline Food insecurity & -.02 & & & \\
\hline Courses organized after Covid & $-.14 * * *$ & & -.10 & $28 \%$ \\
\hline Perceived professor support & -.02 & & & \\
\hline Perceived peer academic support & $-.07 * *$ & & -.04 & $40 \%$ \\
\hline Perceived academic advising support & $-.07 * * *$ & & -.03 & $52 \%$ \\
\hline Depression (PHQ-9) & & $.54 * * *$ & .37 & \\
\hline $\mathrm{N}=$ & 1720 & 1780 & 1722 & \\
\hline adjusted $R^{2}\left(\triangle R^{2}\right)$ & $.348(.296)$ & $.354(.299)$ & $.453(.101)$ & \\
\hline \multicolumn{5}{|c|}{$\begin{array}{l}\text { All variables are scaled from } 0 \text { to } 1.0 \text {. Betas (b) are unstandardized coefficients. } \\
\text { All models control for gender, race, year in school, college, first generation in college, family income, born in U.S. } \\
\triangle \mathrm{R}^{2} \text { for Models } 1 \text { and } 2 \text { are from a model with social background and control variables (not shown). } \\
{ }^{*} \mathrm{p}<.05, * * \mathrm{p}<.01, * * * \mathrm{p}<.001\end{array}$} \\
\hline
\end{tabular}


Figure 1. Trouble Concentrating by Professor Support Explaining Academic Performance.

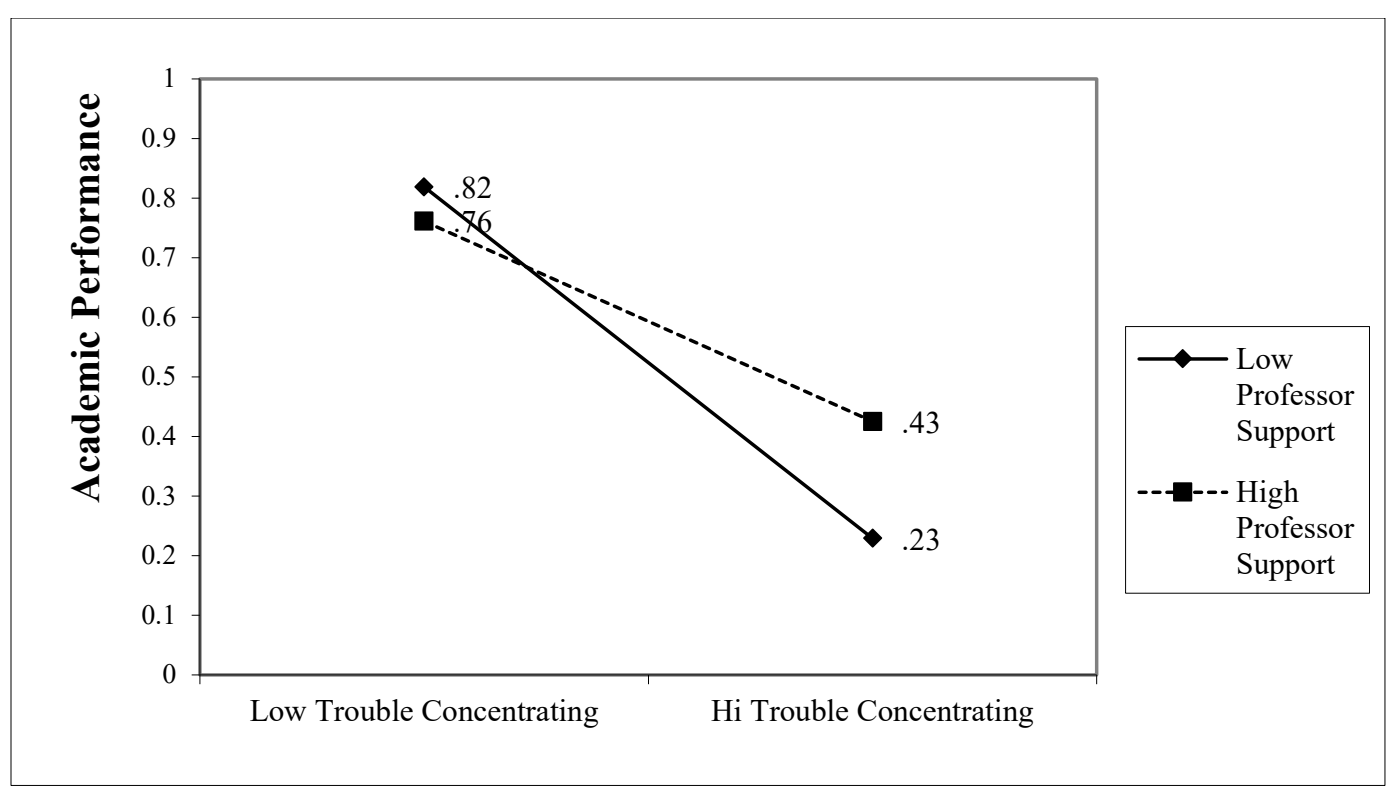

